\title{
Closing the gap in postfracture care at the population level: a randomized controlled trial
}

\author{
William D. Leslie MD MSc, Lisa LaBine MSc, Penny Klassen BSc, Darlene Dreilich BMR (OT), \\ Patricia A. Caetano PhD
}

See related commentary by Majumdar on page 279 and at www.cmaj.ca/lookup/doi/10.1503/cmaj.111999

Competing interests: William D. Leslie has received speaker fees from Merck Frosst and Amgen; he has unrestricted research grants from Merck Frosst,

Sanofi-Aventis, Procter and Gamble, Novartis, Amgen and Genzyme; he is on the advisory boards for Genzyme, Novartis, and Amgen. Patricia A. Caetano has received an unrestricted research grant from Amgen. No other competing interests were declared.

This article has been peer reviewed.

Correspondence to: Dr. William D. Leslie, bleslie@sbgh.mb.ca

CMAJ 2012. DOI:10.1503 /cmaj.111158

\section{Abstract}

Background: Postfracture care is suboptimal, and strategies to address this major gap in care are necessary. We investigated whether notifications sent by mail to physicians and patients would lead to improved postfracture care.

Methods: We conducted a randomized controlled trial (ClinicalTrials.gov identifier NCT00594789) in the province of Manitoba, Canada, from June 2008 to May 2010. Using medical claims data, we identified 4264 men and women age 50 years or older who recently reported major fractures, and who had not undergone recent bone mineral density testing or treatment for osteoporosis. Participants were randomized to three groups: group 1 received usual care $(n=1480)$, patients in group 2 had mailed notification of the fracture sent to their primary care physicians $(n=1363)$, and group 3 had notifications sent to both physicians and patients $(n=1421)$. Bone mineral density testing and the start of pharmacologic treatment for osteoporosis within the following 12 months were documented.
Results: Among participants in group 1 (usual care), $15.8 \%$ of women and $7.6 \%$ of men underwent testing for bone mineral density or started pharmacologic treatment for osteoporosis. Outcome measures improved among participants in group 2 (30.3\% of women and $19.0 \%$ of men, both $p<0.001)$ and group $3(34.0 \%$ of women and $19.8 \%$ of men, both $p<0.001$ ). No additional benefit was seen with patient notification in addition to physician notification. Combining groups 2 and 3, the absolute increase for the combined end point of bone mineral density testing or pharmacologic treatment was $14.9 \%$ (16.4\% among women, $11.8 \%$ among men). The number needed to notify to change patient care was 7 ( 6 for women, 6 for men). The adjusted odds ratio (OR) to change patient care in group 2 was 2.45 (95\% confidence interval [CI] 2.01-2.98); for group 3 the OR was 2.82 (95\% Cl 2.33-3.43).

Interpretation: This notification system provides a relatively simple way to enhance postfracture care.
$\mathrm{T}$ he recently published 2010 clinical practice guidelines for osteoporosis care in Canada identified a large "care gap" for people who have sustained fragility fractures. ${ }^{1}$ Most of the people who have had a major osteoporotic fracture (more than $80 \%$ in a recent Manitoba study) do not undergo testing for bone mineral density or pharmacologic treatment to assist in preventing further fractures. ${ }^{2,3}$ This gap in care is a missed opportunity for secondary prevention, because people who have already sustained a fragility fracture are at much higher risk for recurrent fractures. ${ }^{4}$

Educational initiatives are necessary but are insufficient for effecting a system-wide improvement in care. ${ }^{5,6}$ Although such initiatives can have short-term benefits, they do not produce long-term changes in postfracture care..$^{7,8}$ Approaches that target the health care system and process of care have the potential to effect broad and long-term changes in patient care. ${ }^{910}$

Administrative health care data provide a convenient source of population-based information. In theory, these data might permit identification of incident fractures with targeted notification aimed at improving care.

We investigated whether notifying the primary care physicians associated with patients' long-term care and providing them with simple information on appropriate management would help to close the gap in care, and whether the addition of patient notification would further enhance this initiative.

\section{Methods}

\section{Study design}

We conducted a randomized controlled trial (ClinicalTrials.gov identifier NCT00594789) in 
Manitoba, Canada, using administrative health care data collected by the provincial ministry, Manitoba Health. The design and implementation of this study has been previously described. ${ }^{11}$ Briefly, eligible men and women 50 years of age or older with a recently reported fracture of the hip, spine, humerus or forearm were randomized to one of three groups. The intervention consisted of a mailed letter to primary care physicians, or to patients and primary care physicians, notifying them of the recent fracture and suggesting follow-up for the assessment of osteoporosis. Randomization occurred from June 1, 2008, to May 31, 2010, and included an initial six-month look back to identify recent diagnoses of fracture. Participants were followed to the end of May 31, 2011. Access to the administrative health care data for this project was approved by Manitoba's Health Information Privacy Committee, and the study was approved by the University of Manitoba Health Research Ethics Board.

\section{Data sources}

Manitoba Health maintains comprehensive, population-based, administrative health care databases that include medical billings, information on admissions to hospital, and prescriptions dispensed from outpatient pharmacies without age restrictions. Each of these databases is patient-specific, with unique personal identifiers that allow linkage across databases.

Since 1997, testing bone mineral density in Manitoba has been managed by the Manitoba Bone Mineral Density Program Committee. All clinical bone densitometry is done within this program, which maintains uniform testing indications, requisitions and reporting. The program maintains a population-based database with completeness and accuracy in excess of $99 \% .^{12}$

\section{Study population}

We included men and women 50 years of age and older at the time of fracture with a physician billing record containing one of the following diagnoses from the International Classification of Diseases, 9th Revision (Clinical Modification) (ICD-9-CM): fracture of the hip (ICD-9-CM codes 820 and 821 , plus a procedure code for site-specific reduction or fixation of fracture, open or closed); spine (ICD-9-CM 805); humerus (ICD-9-CM 812); or forearm (ICD-9-CM 813, plus a procedure code for site-specific reduction or fixation of fracture, open or closed, or application of a cast). Physician claims data show a high positive predictive value for acute fractures confirmed radiographically, and this value is further enhanced by orthopedic intervention codes. ${ }^{13}$
We did not attempt to exclude nonosteoporotic causes of fracture (e.g., major trauma), as these are difficult to identify in physician claims data. In addition, most (over 80\%-90\%) major fractures that occur after the age of 50 years are related to a fragility mechanism..$^{14}$

To identify incident fractures and to ensure that no more than one notification would be sent per year, we excluded men and women with a physician or hospital claim showing a fracture in the 12 months before the most recent fracture. We also excluded patients who were taking medication for osteoporosis, as identified through the pharmaceutical claims database (prescriptions filled for bisphosphonate drugs, selective estrogen receptor modulators, calcitonin, systemic estrogen or teriparatide), and patients who had received a bone mineral density test within the three years before sustaining a fracture, were excluded. In addition, patients who were not residents of Manitoba or who had cancelled their coverage with Manitoba Health were not eligible for the study. Finally, we excluded residents of nursing homes, as data on the use of medications for that population are incomplete.

\section{Randomization groups}

Manitoba Health randomized the cohort using a centralized computer-based algorithm that concealed the allocation process from the clinical investigators. Participants were allocated to one of the following three groups: usual care, physician notification, and physician and patient notification.

For the group receiving usual care, neither physicians nor patients received any targeted notification. This group thus served as the control group. In keeping with standard care, this group was not denied access to bone mineral density testing or treatment for osteoporosis.

For participants in the second group, the patient's primary care physician (identified from medical billings under the "General/Family Physician" specialty code; physician who most frequently cared for the patient within two years of the fracture) was sent a letter notifying him or her of the patient's fracture. If a primary care physician could not be identified (about $10 \%-15 \%$ of fractures), the letter was sent to the physician who provided the initial care for the fracture. The letter included the patient's name, date of birth, provincial health number and the date of the fracture. The letter directed the physician to the provincial guidelines on bone mineral density testing and provided information on the management of osteoporosis. Additional information specific to our research initiative was also provided. Enclosed with the letter were a requisition for a bone mineral density test and a flowchart showing the management of care. ${ }^{11}$ 
Participants in the third group received a letter of notification, as did their primary care physicians. The letter sent to patients acknowledged their recent fracture and briefly stated that fractures in older people may suggest osteoporosis. Patients were encouraged to see their family physician to determine whether further testing or treatment for osteoporosis was necessary. For patients who did not have a regular family physician, a phone number for the Family Doctor Connection — a provincial program identifying family physicians who are accepting new patients - was provided. In addition, patients were informed that they could contact the physician who initially treated their fracture.

\section{Outcomes}

Bone mineral density testing, the start of medication for osteoporosis or a combination of the two were assessed for 12 months postfracture using the population-based data sources described earlier. The primary outcome was the combined end point of postfracture bone mineral density testing or the start of medication for osteoporosis.

\section{Statistical analysis}

All eligible participants were included in an intention-to-treat analysis, including those participants with fewer than 12 months of observation owing to death $(n=406)$ or leaving the province $(n=$ 190). The study was powered to identify a beneficial effect on management (over $90 \%$ power to detect an absolute increase of $10 \%$ in the combined rate of bone mineral density testing and pharmacologic treatment of osteoporosis with $\alpha=$ $0.05)$. The selection of a $10 \%$ minimal clinically important difference was based on previous randomized controlled trials done in Canada to test educational and process-of-care initiatives.

Bone mineral density testing and the start of osteoporosis pharmacotherapy were analyzed as separate end points. We used unadjusted analyses $\left(\chi^{2}\right.$ test) and covariate-adjusted analyses (logistic regression). Relevant covariates were age group, sex and the site of the fracture. A $p$ value of less than 0.05 showed a significant effect.

We also compared results between residents of urban (Winnipeg) and rural areas.

\section{Results}

A total of 4264 people (67\% women, 33\% men) met our inclusion criteria (Figure 1). From this total, 1480 patients were randomized to the control group receiving usual care, 1363 were placed in the group whose physicians received notification of their fractures, and 1421 were placed in the group where patients and physicians received notification letters. The groups were well balanced in terms of age, sex and site of fracture (Table 1). The forearm was the most frequent site of fracture $(31.9 \%)$; spinal fractures were the least frequent $(15.2 \%)$.

Within 12 months of sustaining a fracture, $15.8 \%$ of women and $7.6 \%$ of men in the group receiving usual care had either undergone bone mineral density testing or started pharmacologic treatment for osteoporosis $(p<0.001$ for gender

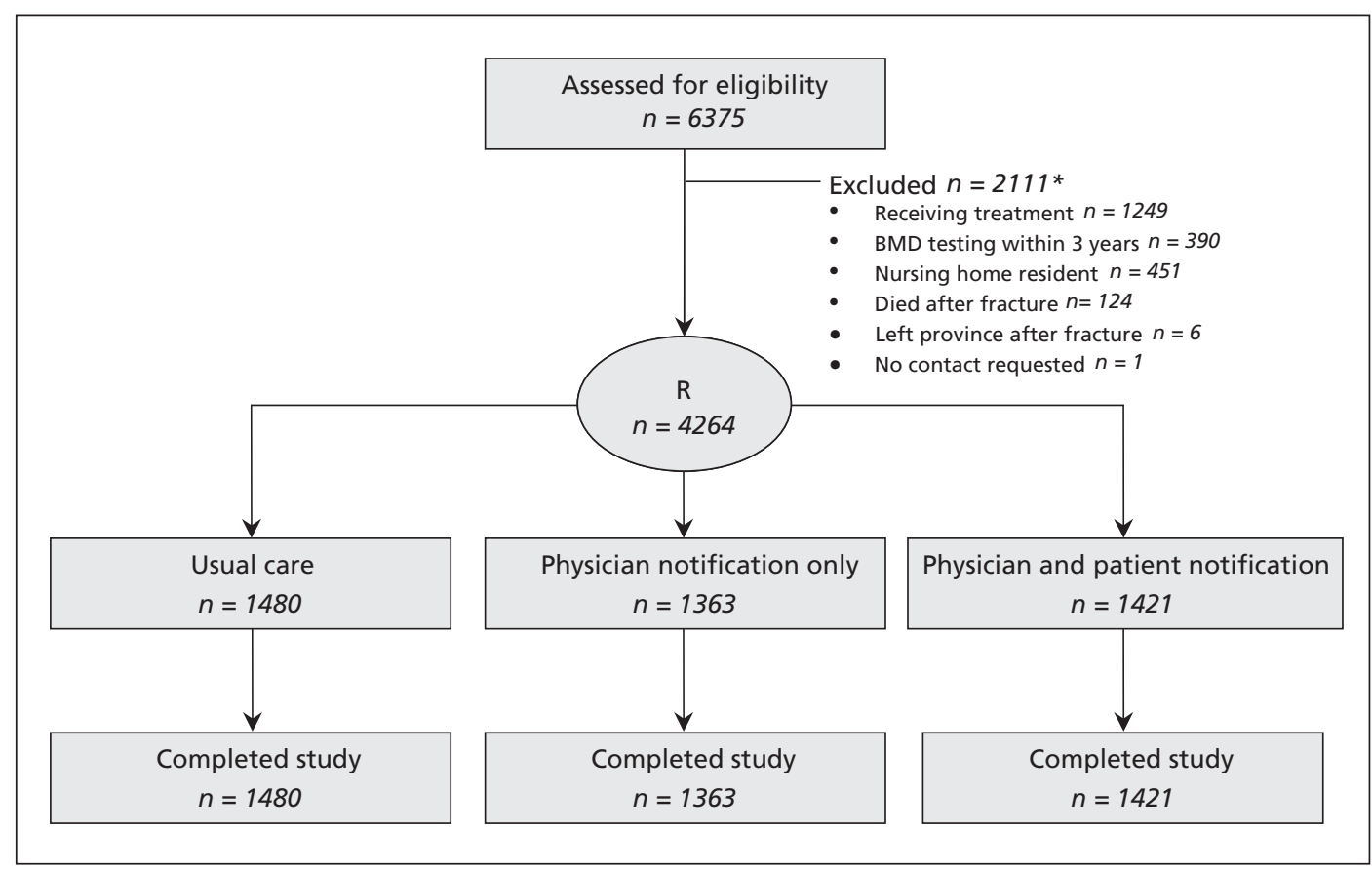

Figure 1: Flow of patients through the trial. $\mathbf{R}=$ randomization. *Some patients were excluded for more than one reason. 
difference) (Table 2). Bone mineral density testing was done less frequently than pharmacologic treatment for both women $(5.7 \%$ v. $12.2 \%, p<$ $0.001)$ and men $(0.4 \%$ v. $7.3 \%, p<0.001)$ in the group receiving usual care (Table 2 ). Both notification groups (physician only, and patient and physician) showed an increase in postfracture care whether in terms of bone mineral density testing, pharmacologic treatment for osteoporosis or the combined end point (Table 2).

When the two notification groups were combined, the absolute increase over usual care for bone mineral density testing was $13.4 \%$ (14.6\% for women, $11.1 \%$ for men); the corresponding increase for starting pharmacologic treatment for osteoporosis was 5.0\% (6.0\% for women, 3.0\% for men); for either bone mineral density testing or pharmacologic treatment, the absolute increase was $14.9 \%$ (16.4\% for women, $11.8 \%$ for men).

The absolute increase over usual care in the combined end point for the two notification groups was similar for the different fracture sites (ranging from $12.6 \%$ for fractures of the forearm to $17.1 \%$ for fractures of the humerus) and for the different locations of patients in the province ( $14.1 \%$ for Winnipeg v. $15.9 \%$ for rural Manitoba) (data not shown). The number needed to notify to change patient care, as measured by bone mineral density testing or the start of pharmacologic treatment, was 7 (6 for women, 8 for men).

We used logistic regression analysis to identify factors predicting postfracture care (Table 3 ). We saw no significant difference between the two groups receiving notifications. Both of these groups showed a large effect of notification on bone mineral density testing (odds ratio [OR] $4.73,95 \%$ confidence interval $[95 \% \mathrm{CI}] 3.49$ 6.40 for physician notification; OR 5.50, 95\% CI

Table 1: Baseline characteristics of 4264 patients with fractures included in the study

\begin{tabular}{|c|c|c|c|c|}
\hline \multirow[b]{2}{*}{ Characteristic } & \multicolumn{3}{|c|}{ Intervention } & \multirow[b]{2}{*}{$\begin{array}{c}\text { Overall } \\
n=4264\end{array}$} \\
\hline & $\begin{array}{c}\text { Usual care, } \\
\text { no. }(\%) \\
n=1480\end{array}$ & $\begin{array}{c}\text { Physician } \\
\text { notification, } \\
\text { no. }(\%) \\
n=1363\end{array}$ & $\begin{array}{c}\text { Physician and } \\
\text { patient } \\
\text { notification, } \\
\text { no. }(\%) \\
n=1421\end{array}$ & \\
\hline \multicolumn{5}{|l|}{ Age group, yr } \\
\hline 50-59 & 340 (22.9) & 391 (28.7) & $384(27.0)$ & $1115(26.1)$ \\
\hline $60-69$ & 281 (18.9) & $297(21.8)$ & $297(20.9)$ & $875(20.5)$ \\
\hline 70-79 & 322 (21.7) & $285(20.9)$ & $286(20.9)$ & 893 (20.9) \\
\hline$\geq 80$ & $537(36.3)$ & $390(28.6)$ & 454 (31.9) & $1381(32.4)$ \\
\hline \multicolumn{5}{|l|}{ Sex } \\
\hline Female & 990 (66.9) & $920(67.5)$ & $931(65.5)$ & 2841 (66.6) \\
\hline Male & $490(33.1)$ & $443(32.5)$ & 490 (34.5) & $1423(33.4)$ \\
\hline \multicolumn{5}{|l|}{ Residence } \\
\hline Urban & $936(63.2)$ & 771 (56.6) & 818 (57.6) & $2524(59.2)$ \\
\hline Rural & $545(36.8)$ & $592(43.4)$ & $603(42.4)$ & $1740(40.8)$ \\
\hline \multicolumn{5}{|l|}{ Fracture site } \\
\hline Hip & $374(25.3)$ & $283(20.8)$ & $296(20.8)$ & $953(22.3)$ \\
\hline Forearm & $423(28.5)$ & 448 (32.9) & $488(34.3)$ & 1359 (31.9) \\
\hline Spine & $219(14.8)$ & $209(15.3)$ & $219(15.4)$ & $647(15.2)$ \\
\hline Humerus & 464 (31.4) & $423(31.0)$ & $418(29.4)$ & $1305(30.6)$ \\
\hline
\end{tabular}

Table 2: Postfracture care among women, men and all patients combined for each of the interventions studied

\begin{tabular}{|c|c|c|c|c|}
\hline $\begin{array}{l}\text { Bone mineral density } \\
\text { testing }\end{array}$ & $56 \quad(5.7,4.2-7.1)$ & $171(18.6,15.9-21.3)$ & $204(21.9,19.4-24.4)$ & $375(20.3,18.4-22.1)$ \\
\hline Men only & $n=490$ & $n=443$ & $n=490$ & $n=933$ \\
\hline $\begin{array}{l}\text { Bone mineral density } \\
\text { testing }\end{array}$ & $2 \quad(0.4,0.0-1.0)$ & $53(11.9,9.0-14.9)$ & $54(11.0,8.1-13.9)$ & $107(11.5,9.4-13.5)$ \\
\hline Pharmacologic treatment & $36 \quad(7.3,5.0-9.7)$ & $44 \quad(9.9,7.0-12.8)$ & $53(10.8,8.2-13.5)$ & $97(10.4,8.4-12.4)$ \\
\hline Testing or treatment & $37 \quad(7.6,2.0-9.9)$ & $84(19.0,15.3-22.7)$ & $97(19.8,16.3-23.3)$ & $181(19.4,16.9-21.9)$ \\
\hline Pharmacologic treatment & $157(10.6,9.0-12.2)$ & $200(14.7,12.7-16.6)$ & $234(16.5,14.6-18.3)$ & $434(15.6,14.2-16.9)$ \\
\hline Testing or treatment & $193(13.0,11.3-14.8)$ & $363(26.6,24.2-29.0)$ & $414(29.1,26.8-31.4)$ & $777(27.9,26.2-29.6)$ \\
\hline
\end{tabular}


4.08-7.42 for patient and physician notification), with a smaller but still significant effect on starting pharmacologic treatment (OR 1.53, 95\% CI 1.22-1.92 for physician notification; OR 1.77, 95\% CI 1.42-2.21 for patient and physician notification). Using the combined end point of testing or treatment, we found that the odds of the primary outcome more than doubled (OR 2.45, 95\% CI 2.01-2.98 for physician notification; OR $2.82,95 \%$ CI $2.33-3.43$ for patient and physician notification). Men were significantly less likely than women to receive either form of postfracture care (all $p<0.001$ ).

Compared with patients aged 50-59 years, older patients were more likely to start pharmacologic treatment for osteoporosis, and patients aged 60-69 years and 70-79 years were more likely to undergo bone mineral density testing; patients aged 80 years and older were less likely than patients aged 50-59 years to undergo bone mineral density testing (Table 3 ).

Pharmacologic treatment was more likely to be started after a spinal fracture (OR 2.51, 95\% CI 1.93-3.28) than after a fracture of the forearm (the reference fracture site) (Table 3). In contrast, bone mineral density testing was less likely after a fracture of the spine (OR $0.62,95 \%$ CI 0.45 0.85 ), hip (OR $0.65,95 \%$ CI $0.57-0.90$ ) or humerus (OR $0.72,95 \%$ CI $0.57-0.90$ ) than after a fracture of the forearm (Table 3 ).

\section{Interpretation}

\section{Main findings}

This randomized controlled trial confirmed the feasibility of using administrative health care data to change patterns of postfracture care as measured by bone mineral density testing, starting pharmacologic treatment or a combined end point. The low rates of postfracture intervention in the group receiving usual care, particularly among men, highlight the scale of the gap in care. Furthermore, this strategy is suitable for implementation on a population level and in areas where population density would not easily support a case-management strategy, providing that high-quality administrative data are available.

We saw no additional benefit in notifying patients in addition to their physicians.

\section{Comparison with other studies}

The need to break the "fragility fracture cycle" was recently highlighted as an international challenge. ${ }^{15} \mathrm{~A}$ systematic review found that $65 \%$ of clinical systems for ensuring appropriate postfracture care include a dedicated case coordinator. ${ }^{16}$ In some countries, a liaison service for fractures has been cost-effective. ${ }^{17,18}$ In the United States, by aggressively identifying and managing the care of patients with osteoporosis, one group reported a $37.2 \%$ reduction in hip fractures and

Table 3: Factors predicting postfracture care*

\section{Care received}

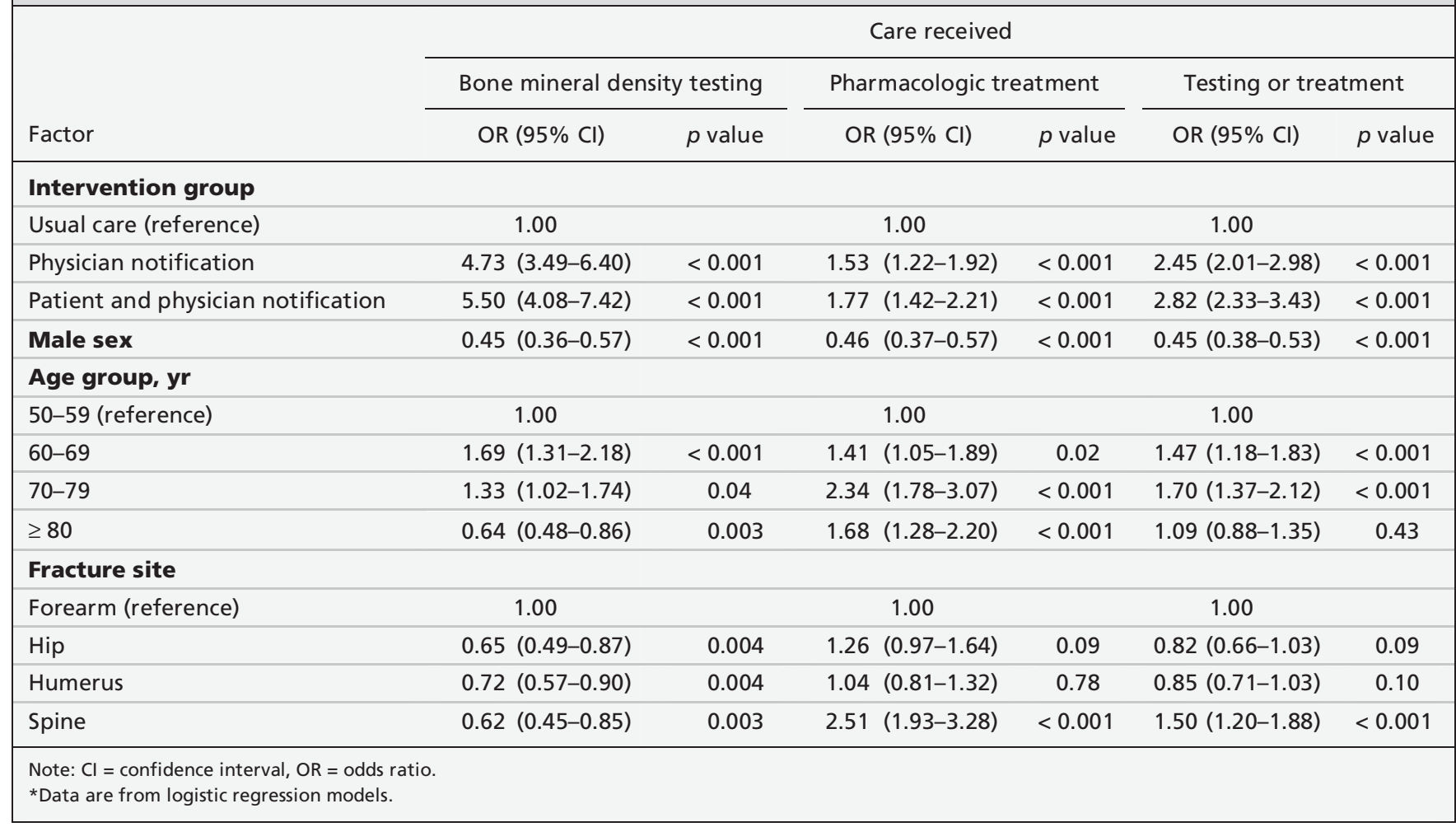


estimated savings of more than US $\$ 30.8$ million. ${ }^{9}$ In the Canadian context, the use of dedicated case managers after a hip fracture was both effective and economical, and projected to be cost-saving. ${ }^{19}$ A multifaceted intervention was also effective following an acute fracture of the forearm,,$^{20,21}$ and a recent study showed even greater benefit with a nurse in the role of case manager. ${ }^{22}$ Even higher success rates have been reported when coordinated postfracture education about osteoporosis is used in combination with a treatment program, but such a program required a dedicated coordinator and the full cooperation of orthopaedic surgeons and residents, orthopaedic technologists, allied health care professionals and administrative staff. ${ }^{23}$

For smaller communities, a multifaceted intervention in which a centralized osteoporosis coordinator followed-up with patients by telephone and with their primary care physicians by mail, and assisted patients with arranging telehealth consultations when necessary, was effective in improving osteoporosis care. ${ }^{24}$

The recently published 2010 clinical practice guidelines for osteoporosis care in Canada recommended case management as an effective approach to postfracture care (grade A). ${ }^{1}$ Our approach, using simple mailed notifications, does not replace other approaches. However, it may complement and reinforce other strategies given its low cost ( $\$ 6.50$ per notification during the study period, with ongoing direct mailing costs of $\$ 1.25$ per notification $^{18}$ ) and applicability at the population level.

\section{Limitations}

Despite the substantial improvements in the rates of postfracture care received, a large gap in care persisted. The highest level of care (bone mineral density testing and pharmacologic treatment) was seen among women, but it barely exceeded $30 \%$.

There are several possible explanations for why a higher rate of success was not achieved. One of the requirements for conducting this study was that we include a covering letter from Manitoba Health describing the intervention as a research study. For this reason, recipients may have failed to appreciate that enhancing patient care was the study's objective and, consequently, may not have read the subsequent information. Alternatively, the physician contacted may no longer have been the patient's primary care physician and may not have felt a duty of care, or the fracture may not have warranted further investigation for osteoporosis (e.g., major trauma or malignancy). In addition, it is possible that a patient declined further evaluation, or had underlying conditions that were felt to preclude a meaningful benefit (e.g., limited quality of life or survival), as fragility fractures are markers of frailty and increased risk of death. ${ }^{25}$ For some patients, nonpharmacologic interventions, such as optimizing the patient's diet and fall prevention (which cannot be identified in administrative data), may have been considered sufficient.

It is difficult to know the so-called "right" level of treatment postfracture. Using acute myocardial infarction as an analogy, ${ }^{26}$ postfracture care with the aim of secondary prevention approaching $80 \%$ may not be unreasonable for fractures of the spine and hip where there is evidence that treatment is effective independent of bone mineral density testing..$^{27,28}$ For other fractures, bone mineral density testing with selective pharmacologic treatment may be more appropriate. ${ }^{29}$ If only those patients with bone density test results that show osteoporosis are treated, then about half of women and one-quarter of men with fractures of the forearm or humerus would receive treatment. ${ }^{17}$

\section{Conclusion}

Creative strategies are needed to enhance postfracture care, which remains suboptimal. A relatively simple process using mailed notifications to physicians improves, but does not close, the gap in postfracture care. Additional strategies, possibly used in combination, may be more successful but need to be developed and tested. Future research should attempt to identify postfracture interventions that lead to appropriate guidelines-based care ${ }^{1}$ and translate into a reduction of recurrent fractures.

\section{References}

1. Papaioannou A, Morin S, Cheung AM, et al. 2010 clinical practice guidelines for the diagnosis and management of osteoporosis in Canada: summary. CMAJ 2010;182:1864-73.

2. Giangregorio L, Papaioannou A, Cranney A, et al. Fragility fractures and the osteoporosis care gap: an international phenomenon. Semin Arthritis Rheum 2006;35:293-305.

3. Leslie WD, Giangregorio LM, Yogendran M, et al. A populationbased analysis of the post-fracture care gap 1996-2008: the situation is not improving. Osteoporos Int 2011 Apr. 8 [Epub ahead of print].

4. Kanis JA, Johnell O, De Laet C, et al. A meta-analysis of previous fracture and subsequent fracture risk. Bone 2004;35:375-82.

5. Hansen KE, Rosenblatt ER, Gjerde CL, et al. Can an online osteoporosis lecture increase physician knowledge and improve patient care? J Clin Densitom 2007;10:10-20.

6. Jaglal SB, Hawker G, Bansod V, et al. A demonstration project of a multi-component educational intervention to improve integrated post-fracture osteoporosis care in five rural communities in Ontario, Canada. Osteoporos Int 2009;20:265-74

7. Hawker G, Ridout R, Ricupero M, et al. The impact of a simple fracture clinic intervention in improving the diagnosis and treatment of osteoporosis in fragility fracture patients. Osteoporos Int 2003; $14: 171-8$

8. Solomon DH, Katz JN, Finkelstein JS, et al. Osteoporosis improvement: a large-scale randomized controlled trial of patient and primary care physician education. J Bone Miner Res 2007;22:1808-15.

9. Dell R, Greene D, Schelkun SR, et al. Osteoporosis disease management: the role of the orthopaedic surgeon. J Bone Joint Surg Am 2008;90(Suppl 4):188-94.

10. Ayoub WT, Newman ED, Blosky MA, et al. Improving detection and treatment of osteoporosis: redesigning care using the electronic medical record and shared medical appointments. Osteoporos Int 2009;20:37-42. 
11. Caetano PA, LaBine L, Klassen $\mathrm{P}$, et al. Closing the postfracture care gap using administrative health databases: design and implementation of a randomized controlled trial. J Clin Densitom 2011; 14:422-7.

12. Leslie WD, Caetano PA, MacWilliam LR, et al. Construction and validation of a population-based bone densitometry database. J Clin Densitom 2005;8:25-30.

13. Jean S, Candas B, Belzile E, et al. Algorithms can be used to identify fragility fracture cases in physician-claims databases. Osteoporos Int 2011 Feb. 19 [Epub ahead of print] .

14. Mackey DC, Lui LY, Cawthon PM, et al. High-trauma fractures and low bone mineral density in older women and men. JAMA 2007;298:2381-8.

15. Sale JE, Beaton D, Posen J, et al. Systematic review on interventions to improve osteoporosis investigation and treatment in fragility fracture patients. Osteoporos Int 2011;22:2067-82.

16. Marsh D, Akesson K, Beaton DE, et al. Coordinator-based systems for secondary prevention in fragility fracture patients. Osteoporos Int 2011;22:2051-65.

17. McLellan AR, Gallacher SJ, Fraser M, et al. The fracture liaison service: success of a program for the evaluation and management of patients with osteoporotic fracture. Osteoporos Int 2003;14: 1028-34.

18. McLellan AR, Wolowacz SE, Zimovetz EA, et al. Fracture liaison services for the evaluation and management of patients with osteoporotic fracture: a cost-effectiveness evaluation based on data collected over 8 years of service provision. Osteoporos Int 2011; 22:2083-98.
19. Majumdar SR, Lier DA, Beaupre LA, et al. Osteoporosis case manager for patients with hip fractures: results of a costeffectiveness analysis conducted alongside a randomized trial. Arch Intern Med 2009;169:25-31.

20. Cranney A, Lam M, Ruhland L, et al. A multifaceted intervention to improve treatment of osteoporosis in postmenopausal women with wrist fractures: a cluster randomized trial. Osteoporos Int 2008;19:1733-40

21. Majumdar SR, Johnson JA, McAlister FA, et al. Multifaceted intervention to improve diagnosis and treatment of osteoporosis in patients with recent wrist fracture: a randomized controlled trial. CMAJ 2008;178:569-75.

22. Majumdar SR, Johnson JA, Bellerose D, et al. Nurse case-manager vs multifaceted intervention to improve quality of osteoporosis care after wrist fracture: randomized controlled pilot study. Osteoporos Int 2011;22:223-30.

23. Bogoch ER, Elliot-Gibson V, Beaton DE, et al. Effective initiation of osteoporosis diagnosis and treatment for patients with a fragility fracture in an orthopaedic environment. J Bone Joint Surg Am 2006;88:25-34

24. Jaglal SB, Donescu OS, Bansod V, et al. Impact of a centralized osteoporosis coordinator on post-fracture osteoporosis management: a cluster randomized trial. Osteoporos Int 2011 July 16 [Epub ahead of print].

25. Ioannidis G, Papaioannou A, Hopman WM, et al. Relation between fractures and mortality: results from the Canadian Multicentre Osteoporosis Study. CMAJ 2009;181:265-71.

26. Austin PC, Tu JV, Ko DT, et al. Factors associated with the use of evidence-based therapies after discharge among elderly patients with myocardial infarction. CMAJ 2008;179:901-8.

27. Kanis JA, Barton IP, Johnell O. Risedronate decreases fracture risk in patients selected solely on the basis of prior vertebral fracture. Osteoporos Int 2005;16:475-82.

28. Lyles KW, Colon-Emeric CS, Magaziner JS, et al. Zoledronic acid and clinical fractures and mortality after hip fracture. $N$ Engl J Med 2007;357:1799-809.

29. Ryder KM, Cummings SR, Palermo L, et al. Does a history of non-vertebral fracture identify women without osteoporosis for treatment? J Gen Intern Med 2008;23:1177-81.

Affiliations: From the University of Manitoba (Leslie), and Manitoba Health (LaBine, Klassen, Dreilich, Caetano), Winnipeg, Man.

Contributors: William Leslie, Lisa LaBine, Darlene Dreilich and Patricia Caetano designed the study. William Leslie and Darlene Dreilich secured funding for the study. William Leslie, Lisa LaBine and Patricia Caetano approved the study. William Leslie drafted the manuscript. William Leslie and Penny Klassen analyzed the data. All of the authors interpreted the data, revised the manuscript for important intellectual content and approved the final version submitted for publication.

Funding: Funded by the Manitoba Patient Access Network, whose mandate is to identify, advocate, support and guide health system change and process improvement initiatives. The network is financially supported by the Wait Times Reduction Fund and receives secretariat services from Manitoba Health's Wait Times Task Force.

Acknowledgements: The authors thank Ms. Brie DeMone and Ms. Deborah Malazdrewicz of Manitoba Health for their advice, support, personnel and review of this initiative, and Health Information Management of Manitoba Health for programming and logistical support, and the use of data contained in this report (file no. 2007/2008-31). The results and conclusions are those of the authors and no official endorsement by Manitoba Health is intended or should be inferred. This article has been reviewed and approved by the members of the Manitoba Bone Density Program Committee. 